Article

\title{
Antibacterial Activity of Juglone against Staphylococcus aureus: From Apparent to Proteomic
}

\author{
Jiayi Wang ${ }^{\dagger}$, Yuhuan Cheng ${ }^{\dagger}$, Rina Wu, Donghua Jiang, Bing Bai, Dehong Tan, Tingcai Yan, \\ Xiyun Sun, Qi Zhang and Zhaoxia $\mathrm{Wu}$ * \\ College of Food Science, Shenyang Agricultural University, 120 Dongling Rd., Shenyang 110866, China; \\ jiayiwangsyau@syau.edu.cn (J.W.); 15802496575@163.com (Y.C.); wrn6956@163.com (R.W.); \\ donghuajiang@syau.edu.cn (D.J.); baibingsyau@syau.edu.cn (B.B.); tandehongsy@126.com (D.T.); \\ ytc126127@163.com (T.Y.); sun_xiyun@syau.edu.cn (X.S.); xiaodi1993@163.com (Q.Z.) \\ * Correspondence: wuzhaoxia@syau.edu.cn Tel.: +86-24-8636-4105 \\ + These authors contributed equally to this work.
}

Academic Editor: José Alberto Pereira

Received: 20 April 2016; Accepted: 14 June 2016; Published: 18 June 2016

\begin{abstract}
The proportion of foodborne disease caused by pathogenic microorganisms is rising worldwide, with staphylococcal food poisoning being one of the main causes of this increase. Juglone is a plant-derived 1,4-naphthoquinone with confirmed antibacterial and antitumor activities. However, the specific mechanism underlying its antibacterial activity against Staphylococcus aureus remains unclear. To elucidate the mechanism underlying its antibacterial activity, isobaric tags for relative and absolute quantitation methods of quantitative proteomics were applied for analysis of the 53 proteins that were differentially expressed after treatment with juglone. Combined with verification experiments, such as detection of changes in DNA and RNA content and quantification of oxidative damage, our results suggested that juglone effectively increased the protein expression of oxidoreductase and created a peroxidative environment within the cell, significantly reducing cell wall formation and increasing membrane permeability. We hypothesize that juglone binds to DNA and reduces DNA transcription and replication directly. This is the first study to adopt a proteomic approach to investigate the antibacterial mechanism of juglone.
\end{abstract}

Keywords: juglone; Staphylococcus aureus; iTRAQ; antibacterial activity

\section{Introduction}

Food-borne diseases (FBD) are defined by the World Health Organization (WHO) as "diseases of infectious or toxic nature caused by, or thought to be caused by, the consumption of food or water [1]." Numerous food-borne diseases, including staphylococcal food poisoning (SFP), are caused by ingestion of microbial and plant toxins [2], and SFP is mainly caused by Staphylococcus aureus [3]. SFP causes various symptoms, including copious vomiting, diarrhea, abdominal pain, and nausea [4], owing to the production of staphylococcal enterotoxins (SEs). Although approximately 22 SEs [3] are known, only a few of these proteins, such as SEA and SEB, are related to FBD [5]. Hence, it is imperative to control the spread of $S$. aureus to ensure food safety.

Natural products with pharmacological properties often exhibit broad-spectrum antibacterial activity and have unique advantages. Naphthoquinones, such as juglone, lawsone, plumbagin, and lapachol, are natural products with high antibacterial activity. In particular, juglone (5-hydroxy-1,4-naphthoquinone) (Figure 1) has been used for centuries in folk medicines to cure acne, allergies, gastrointestinal disorders, intestinal parasitosis, cancer, fungal infections, bacterial infections, and viral infections [6]. Our previous study revealed that juglone shows antibacterial activity against S. aureus, Escherichia coli, Bacillus subtilis, Penicillium sp., Aspergillus sp., and Hansenula sp. [7]. 
According to previous studies, naphthoquinones exert their antimicrobial, antiparasitic, and cytotoxic activities via several mechanisms, including inhibition of electron transport, uncoupling effects during oxidative phosphorylation, intercalation of agents into the DNA double helix, reduction of alkylating properties of biomolecules, and production of reactive oxygen species (ROS) under aerobic conditions [6]. However, in recent years, most investigations of juglone have focused on its antitumor activity and the related molecular mechanisms. However, a more in-depth understanding of how juglone acts against bacteria, especially S. aureus, is still lacking. Therefore, to elucidate the possible mechanism of action of juglone on S. aureus, we adopted a proteomic approach owing to its suitability for high-volume data processing. Furthermore, proteomics could help reveal changes in the whole proteome post juglone-treatment, in contrast to currently used methods such as superoxide dismutase activity assays, malondialdehyde evaluation, and electron microscopic analysis. In this study, we investigated the proteomic alterations in S. aureus following treatment with juglone using isobaric tags for relative and absolute quantitation (iTRAQ) technology, and then identified the altered proteins to reveal the antibacterial mechanism of juglone.<smiles>O=C1C=CC(=O)c2c(O)cccc21</smiles>

Figure 1. Molecular structure of juglone.

\section{Results and Discussion}

\section{1. iTRAQ Analysis of the Proteome after Treatment with Juglone}

Compared to the initially popular gel-based proteomic technology, MS-based proteomic analyses are now widely used because of their high-throughput capacity, repeatability, and high success rate for protein identification. In the current study, normal S. aureus and S. aureus treated with juglone for $2 \mathrm{~h}$ were collected for protein extraction, digestion, and iTRAQ labeling during the exponential growth phase. As a mainstream MS-based proteomics technology, iTRAQ can provide multiplexing of up to 8-plex isobaric tags including a reporter group, a balance group, and a peptide-reactive group. Once the isobaric tags have reacted with the proteolytic peptides, the balance group is removed to identify the differentially expressed peptides at the second mass spectrometry (MS2) level. In a search using the Mascot 2.2 program, we identified 9834 unique peptides (FDR $\leqslant 0.1$ ), corresponding to 1379 protein groups including 1376 proteins that were quantified by Proteome Discoverer 1.4 in each channel. In total, the expression levels of 53 proteins were shown to be significantly different $(>1.2$-fold change, $p<0.05)$ between treated and untreated cells. Among these proteins, 22 were up-regulated and 31 were down-regulated in the treated cells compared to the untreated cells.

\subsection{Functional Annotation Analysis of Proteomic Differences}

To determine the function of the 53 differentially expressed proteins, we performed annotation analysis using Blast2Go. The proteins were grouped into six categories (Table 1): oxidative damage, DNA replication and transcription, protein synthesis, stress response, cell wall synthesis and cell division, and membrane permeability. 
Table 1. Proteins that showed differential expression following treatment of Staphylococcus aureus with juglone.

\begin{tabular}{|c|c|c|c|c|c|c|c|}
\hline Accession & Protein Name & Gene id & Unique Peptides & Total Peptides & $M w(k D a)$ & Fold Change & $p$-Value \\
\hline \multicolumn{8}{|c|}{ Oxidative damage } \\
\hline Q2FVA5 & glyoxalase & SAOUHSC_02828 & 5 & 5 & 30.00 & 1.824 & 0.012 \\
\hline Q2FZH1 & potassium uptake protein & SAOUHSC_01034 & 2 & 2 & 24.30 & 1.401 & 0.037 \\
\hline Q2FUW1 & serine rich repeat containing protein & sasA & 1 & 1 & 227.90 & 1.406 & 0.027 \\
\hline Q2FWN0 & nitroreductase & SAOUHSC_02258 & 4 & 4 & 24.00 & 1.203 & 0.005 \\
\hline Q2FZD2 & thioredoxin & $\operatorname{trx} \mathrm{A}$ & 9 & 9 & 11.40 & 0.654 & 0.001 \\
\hline Q2G000 & thioredoxin & SAOUHSC_00834 & 6 & 6 & 12.10 & 0.758 & 0.046 \\
\hline Q2FXI6 & thioredoxin & SAOUHSC_01860 & 8 & 8 & 11.80 & 0.781 & 0.003 \\
\hline Q2FZ62 & ribulose-phosphate 3-epimerase & SAOUHSC_01189 & 2 & 2 & 23.60 & 0.750 & 0.038 \\
\hline Q2FWJ9 & threonine dehydratase biosynthetic & ilvA & 3 & 3 & 46.90 & 0.751 & 0.016 \\
\hline Q2FV58 & $\begin{array}{l}\text { 4,4'-diaponeurosporenoate } \\
\text { glycosyltransferase }\end{array}$ & crtQ & 2 & 2 & 42.50 & 0.782 & 0.016 \\
\hline \multicolumn{8}{|c|}{ DNA replication and transcription } \\
\hline Q2FWH6 & DNA-binding response regulator & SAOUHSC_02315 & 2 & 2 & 26.50 & 0.787 & 0.034 \\
\hline Q2FXW6 & uridine kinase & Udk & 3 & 3 & 23.50 & 0.798 & 0.022 \\
\hline Q2FV02 & anaerobic ribonucleoside-triphosphate & SAOUHSC_02942 & 3 & 3 & 70.40 & 0.711 & 0.030 \\
\hline Q2G112 & single-stranded DNA-binding protein & SAOUHSC_00349 & 7 & 7 & 18.50 & 0.816 & 0.014 \\
\hline Q2FZ97 & transcriptional regulator MraZ & mraZ & 3 & 3 & 17.20 & 0.819 & 0.006 \\
\hline Q2FV69 & family transcriptional regulator & SAOUHSC_02867 & 1 & 2 & 21.90 & 0.623 & 0.034 \\
\hline Q2FZK9 & family transcriptional regulator & SAOUHSC_00992 & 2 & 2 & 16.40 & 0.650 & 0.003 \\
\hline Q2G273 & urease accessory protein ureg & ureG & 3 & 3 & 22.30 & 0.796 & 0.021 \\
\hline Q2FXX1 & acetyl- biotin carboxylase subunit & SAOUHSC_01709 & 4 & 4 & 50.20 & 0.761 & 0.022 \\
\hline Q2G1X5 & queuosine biosynthesis protein & SAOUHSC_00720 & 3 & 3 & 16.00 & 0.831 & 0.000 \\
\hline Q2FXT6 & queuine tRNA-ribosyltransferase & $\operatorname{tgt}$ & 2 & 2 & 43.30 & 0.603 & 0.008 \\
\hline \multicolumn{8}{|c|}{ Protein synthesis } \\
\hline Q2FW17 & 50s ribosomal protein 124 & rplX & 2 & 2 & 11.50 & 1.225 & 0.001 \\
\hline Q2FW29 & 50s ribosomal protein 136 & $\mathrm{rpmJ}$ & 1 & 1 & 4.30 & 0.704 & 0.002 \\
\hline Q2FW16 & 50s ribosomal protein 114 & rplN & 4 & 4 & 13.10 & 0.734 & 0.010 \\
\hline Q2FY22 & $50 \mathrm{~S}$ ribosomal protein L33 2 & rpmG2 & 1 & 1 & 5.90 & 0.459 & 0.003 \\
\hline
\end{tabular}


Table 1. Cont.

\begin{tabular}{|c|c|c|c|c|c|c|c|}
\hline Accession & Protein Name & Gene id & Unique Peptides & Total Peptides & $M w(k D a)$ & Fold Change & $p$-Value \\
\hline \multicolumn{8}{|c|}{ Stress response } \\
\hline Q2FUU5 & lipase 1 & $\operatorname{lipA}$ & 2 & 3 & 76.60 & 1.255 & 0.004 \\
\hline Q2FZS8 & chaperone protein $\mathrm{clpB}$ & clpB & 23 & 24 & 98.30 & 1.211 & 0.000 \\
\hline Q2G222 & $\mathrm{N}$-acetylmuramoyl-1-alanine amidase & SAOUHSC_02979 & 11 & 11 & 69.20 & 1.259 & 0.000 \\
\hline Q2G0P6 & ATP:guanido phosphotransferase & $\operatorname{mcsB}$ & 2 & 2 & 38.60 & 1.234 & 0.010 \\
\hline P72360 & iron-sulfur cluster repair di-iron protein & $\operatorname{scd} A$ & 1 & 2 & 25.50 & 0.796 & 0.028 \\
\hline Q2G112 & single-stranded DNA-binding protein & SAOUHSC_00349 & 7 & 7 & 18.50 & 0.816 & 0.014 \\
\hline \multicolumn{8}{|c|}{ Cell wall synthesis and cell division } \\
\hline Q2FUW7 & accessory sec system glycosylation & gtf1 & 1 & 1 & 58.20 & 1.591 & 0.031 \\
\hline Q2G222 & N-acetylmuramoyl-l-alanine amidase & SAOUHSC_02979 & 11 & 11 & 69.20 & 1.259 & 0.000 \\
\hline P72360 & iron-sulfur cluster repair di-iron protein & $\operatorname{scdA}$ & 1 & 2 & 25.50 & 0.796 & 0.028 \\
\hline Q2FZ97 & transcriptional regulator MraZ & mraZ & 3 & 3 & 17.20 & 0.819 & 0.006 \\
\hline Q2FVQ1 & gnat family acetyltransferase & SAOUHSC_02651 & 1 & 1 & 20.10 & 0.669 & 0.019 \\
\hline \multicolumn{8}{|c|}{ Membrane permeability and formation } \\
\hline Q2FZH1 & potassium uptake protein & SAOUHSC_01034 & 2 & 2 & 24.30 & 1.401 & 0.037 \\
\hline Q2FZS8 & chaperone protein clpB & $\mathrm{clpB}$ & 23 & 24 & 98.30 & 1.211 & 0.000 \\
\hline Q2FZD2 & Thioredoxin & trxA & 9 & 9 & 11.40 & 0.654 & 0.001 \\
\hline Q2FXI6 & Thioredoxin & SAOUHSC_01860 & 8 & 8 & 11.80 & 0.781 & 0.003 \\
\hline Q2FXX1 & acetyl- biotin carboxylase subunit & SAOUHSC_01709 & 4 & 4 & 50.20 & 0.761 & 0.022 \\
\hline \multicolumn{8}{|c|}{ Others } \\
\hline Q2FVB3 & antibiotic transport system permease & SAOUHSC_02821 & 1 & 1 & 28.90 & 1.299 & 0.007 \\
\hline Q2FWL8 & transcriptional regulator & SAOUHSC_02271 & 2 & 2 & 8.20 & 1.448 & 0.001 \\
\hline Q2G2L6 & pf09954 family protein & SAOUHSC_02812 & 1 & 1 & 16.00 & 1.383 & 0.019 \\
\hline Q2FZ07 & uncharacterized protein & SAOUHSC_01264 & 2 & 2 & 8.20 & 0.809 & 0.000 \\
\hline Q2FV28 & uncharacterized conserved protein & SAOUHSC_02911 & 2 & 2 & 27.80 & 0.827 & 0.023 \\
\hline Q2G2Q9 & conserved hypothetical family protein & SAOUHSC_00274 & 1 & 2 & 20.10 & 0.586 & 0.001 \\
\hline Q2G297 & metal-dependent phosphohydrolase & SAOUHSC_01696 & 5 & 5 & 22.40 & 0.807 & 0.002 \\
\hline
\end{tabular}




\subsection{Upregulation of Glyoxalase, Potassium Uptake Protein, and Nitroreductase}

After $2 \mathrm{~h}$ of treatment, upregulation of the proteins glyoxalase, potassium uptake protein, and nitroreductase, which belong to the oxidoreductase protein family, was induced by juglone, and resulted in subsequent cell collapse. Additionally, the formation of superoxide radicals is often triggered by metal ions (mostly iron, but also copper, cobalt, and titanium), which are defined as cofactors. These transition metal ions can be transferred from superoxide radicals to hydroxyl free radicals, which are the strongest known oxidizing agents. Such activity may be suggested by the observed up-regulation of serine-rich-repeat-containing protein, which has a calcium-binding function. As shown in Figure 2a, in the groups treated with 12.5, 25, and $37.5 \mu \mathrm{g} / \mathrm{mL}$ juglone, the superoxide dismutase (SOD) activity decreased before $2 \mathrm{~h}$, from 91.07 to $83.15,89.81$ to 80.34 , and 91.59 to $76.79 \mathrm{U} / \mathrm{mgprot}$, respectively. This result suggests that $S$. aureus had not adapted to the excess of superoxide anions before $2 \mathrm{~h}$ and consumed the original SOD to generate hydrogen peroxide, resulting in catalase (CAT) activity increasing from 8.72 to $8.91,8.7$ to 9.42 , and 8.56 to $10.12 \mathrm{U} / \mathrm{mgprot}$ before $2 \mathrm{~h}$, as shown in Figure $2 \mathrm{~b}$. At $4 \mathrm{~h}$, the superoxide anion concentration had far exceeded the capacity of SOD, resulting in the decrease observed after $4 \mathrm{~h}$. Correspondingly, CAT was quickly consumed starting at $4 \mathrm{~h}$. Combined with our proteomic results, these results suggest that juglone could accelerate the redox process leading to oxidative damage to $S$. aureus, and that the cell's own CAT and SOD were not sufficient to cope with the oxidative damage starting at $4 \mathrm{~h}$.

\subsection{Significance of the Downregulation of Thioredoxin, Threonine Dehydratase, and Ribulose-5-phosphate 3-Epimerase-epimerase}

To survive in a peroxidative environment, organisms produce several natural antioxidants, including vitamin C [8], glutathione (GSH) [9], and carotenoids [10], among others. Carotenoids show antioxidative activity based on their ability to trap peroxyl radicals and quench singlet oxygen. Here, 4,4'-diaponeurosporenoate glycosyltransferase, which plays a major role in carotenoid biosynthesis, was down-regulated after treatment with juglone. This result suggested that production of 4,4'-diaponeurosporenoate glycosyltransferase was inhibited by juglone, which resulted in fewer carotenoids in the cells [11]. Moreover, thioredoxin was down-regulated. This protein is a cell redox homeostasis regulator, and its role is to maintain the stability of cellular levels of ROS. Threonine dehydratase was also down-regulated, possibly because of a shortage of iron [12]. Moreover, ribulose-5-phosphate 3-epimerase-epimerase was found to be down-regulated. This molecule in E. coli was reported to be rapidly damaged by hydrogen peroxide [13]; therefore, its down-regulation might have been directly caused by hydrogen peroxide. The change in expression levels of these proteins supports the proposition that oxidative damage was the main mechanism of activity against S. aureus.

\subsection{Downregulation of Proteins Related to DNA Replication and Transcription}

All proteins related to DNA replication and transcription were down-regulated after treatment with juglone for $2 \mathrm{~h}$. DNA-binding response regulator, family transcriptional regulator, and transcriptional regulator MraZ regulate DNA-dependent transcription, while Queuosine biosynthesis protein plays a major role in the tRNA modification process. Queuine is one of the most radically modified nucleosides known to occur in tRNA [14], and its expression level is regulated by queuine tRNA-ribosyltransferase. Other proteins related to DNA transcription, including uridine kinase and urease accessory protein ureg, participate in guanosine triphosphate (GTP) and cytidine triphosphate (CTP) biosynthesis, which plays a major role in the formation and phosphorylation of RNA. Our results suggest that anaerobic ribonucleoside triphosphate and single-stranded DNA-binding protein, which are associated with DNA replication, were also down-regulated. Similarly, as shown in Figure 2d,e, the fluorescence intensity of DNA and RNA in the treated groups maintained a sustained decreasing trend from 0 to $6 \mathrm{~h}$. It was previously reported that juglone induces scission of isolated DNA by reducing glutathione and Fe (II) ions in vitro [15]. In addition, 1,4-naphthoquinones induce oxidative damage to DNA base pairs and accumulation of DNA breaks [16]. The best-known mechanism is 
intercalation between two base pairs of DNA or RNA through the ring of the polycyclic chromophore of quinone. Anthracyclines, which are quinone compounds, exhibit antitumor activity by forming bonds between positively charged amino sugars and the sugar phosphate backbone of DNA [17]. In this manner, several vital biological processes, such as replication and transcription, are blocked. Thus, based on these experimental results, we hypothesize that juglone binds to DNA and directly causes DNA damage.

\subsection{Role of Juglone in Stimulating Stress Response in S. aureus}

DNA damage and oxidative damage can stimulate the stress response in S. aureus. The triglyceride lipase, lipase 1, was also upregulated. Lipase 1 can catalyze use of triacylglycerols (TAG) as a carbon and energy source for survival during starvation conditions [18]. This result suggested that energy metabolism was induced to protect against stress. However, we did not identify upregulation of any proteins related to energy metabolism. This might be attributed to limitations of the database, as 14 of the upregulated proteins could not be annotated and need to be studied further. ATP guanido phosphotransferase and the heat resistance chaperone protein clpB were both upregulated. CtsR-dependent genes were previously shown to be weakly induced in response to oxidative stress; CtsR is a repressor of heat- and stress-specific proteins [19]. However, ATP guanido phosphotransferase acts as a modulator of CtsR repressor activity under oxidative stress [20]. Hence, protein chaperones might be positively regulated by ATP guanido phosphotransferase. Iron-sulfur cluster repair di-iron protein is a di-iron-containing protein involved in repairing iron-sulfur clusters damaged by oxidative and nitrosative stress [21,22]. Chang et al. [23] found that iron-sulfur cluster repair di-iron protein could be induced by hydrogen peroxide, which also supports that juglone acts via oxidative damage. Only one protein, single-stranded DNA-binding protein, related to the DNA damage response was found to be upregulated.

\subsection{Role of Juglone on Protein Synthesis, Cell Wall Formation, and Permeability}

In addition, we noted the impact of juglone on protein synthesis. Three structural components of ribosomes, i.e., 50s ribosomal protein 136, 50s ribosomal protein 114 and 50 S ribosomal protein L33 2, participate in translation and were down-regulated after treatment with juglone. Proteins associated with cell division, i.e., iron-sulfur cluster repair di-iron protein and transcriptional regulator MraZ, were also down-regulated. These results indicate that protein synthesis and cell division were inhibited after treatment with juglone. Figure $2 \mathrm{f}$ shows that in the juglone-treated group, the peptidoglycan content was markedly lower than that in the control group, increasing before $2 \mathrm{~h}$ and decreasing starting at $4 \mathrm{~h}$. Accessory sec system glycosylation protein is an $\mathrm{N}$-acetyltransferase that is part of the SecA2/SecY2 system for synthesis of serine-rich cell wall proteins, and is up-regulation suggested that the formation of the cell wall, was not inhibited before $2 \mathrm{~h}$ of treatment. Similarly, we observed upregulation of $\mathrm{N}$-acetylmuramoyl-1-alanine amidase, an enzyme that catalyzes a chemical reaction that cleaves the link between $\mathrm{N}$-acetylmuramoyl residues and L-amino acid residues in certain cell-wall glycopeptides. These results suggest that cell wall formation was weakly inhibited by $2 \mathrm{~h}$ and strong inhibited starting at $4 \mathrm{~h}$. Moreover, two types protein related to cell membrane synthesis, thioredoxin and acetyl-biotin carboxylase subunit, were down-regulated. Thioredoxin participates in metabolism of glycerol ether, which is an important component of cell membranes. Acetyl-biotin carboxylase subunit has acetyl-CoA carboxylase activity, and multi-subunit acetyl-CoA carboxylase can catalyze the first step in fatty acid biosynthesis [24], promoting cell membrane formation. In Figure 2c, the groups treated with 12.5, 25 , and $37.5 \mu \mathrm{g} / \mathrm{mL}$ juglone, the malondialdehyde (MDA) content steadily increased from initial 0.9 to final $3.78,0.89$ to 4.55 , and 1.19 to $5.43 \mathrm{nmol} / \mathrm{mgprot}$, respectively. These results suggest that cell membrane formation was mainly inhibited through oxidative damage. In addition, potassium uptake protein and chaperone protein $\mathrm{clpB}$, which have cation transmembrane transporter activity, were up-regulated, indicating an increase of permeability. However, gas chromatography analysis (Table 2) showed a decrease in saturated fatty acids (SFA)/ unsaturated fatty acids (UFA), from $1.3 \%$ to $1.21 \%$, 
and ultimately to $1.17 \%$ as the juglone concentration increased. This result suggests that membrane fluidity was increased [25], resulting in increased permeability, consistent with our proteomic analysis.
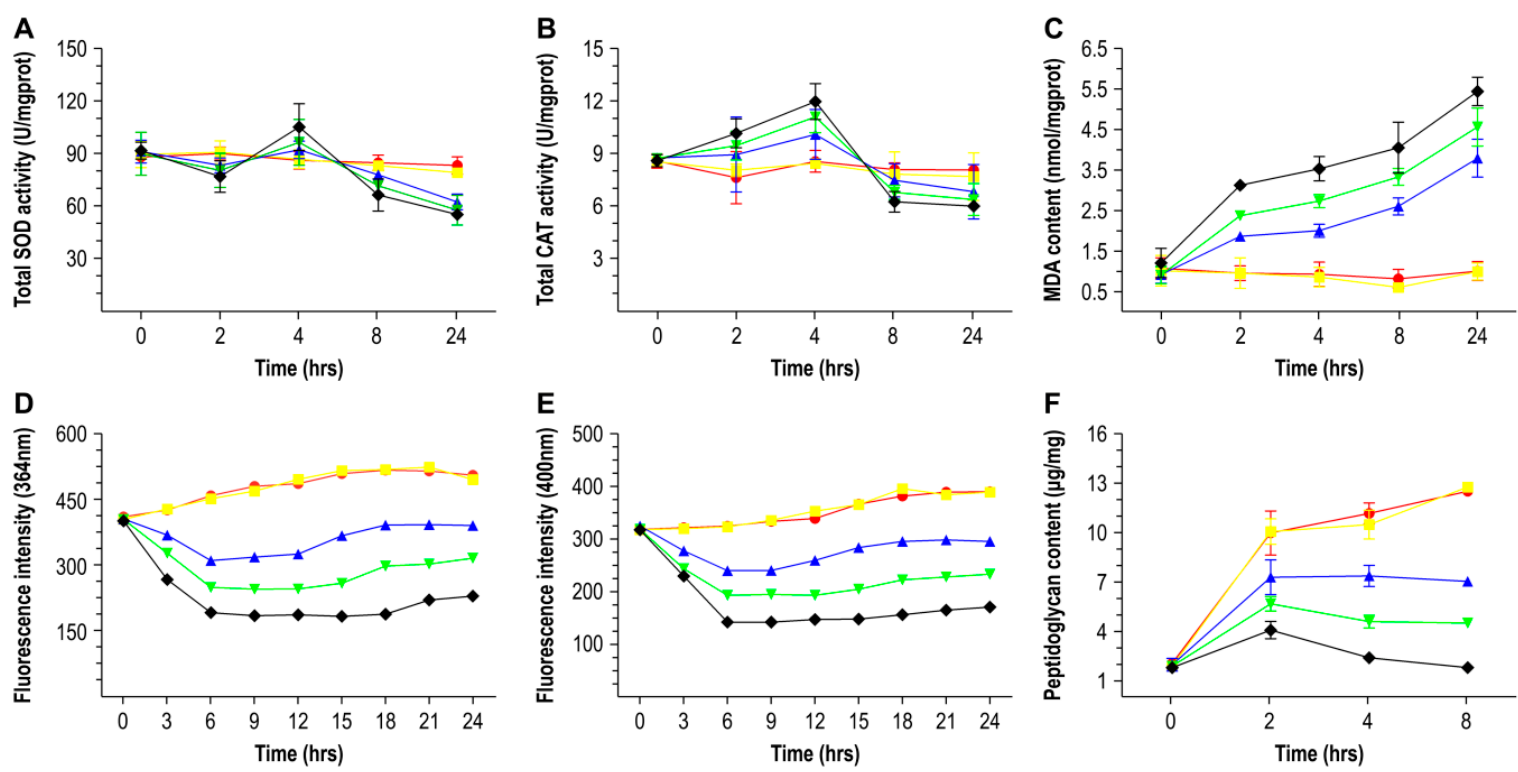

$\multimap$ blank $\multimap$ ethanol $\multimap 12.5 \mu \mathrm{g} / \mathrm{mL} \longrightarrow 25 \mu \mathrm{g} / \mathrm{mL} \longrightarrow 37.5 \mu \mathrm{g} / \mathrm{mL}$

Figure 2. Indicators of damage to Staphylococcus aureus after treatment with juglone. A-C show changes in total superoxide dismutase (SOD) activity, total catalase (CAT) activity, and malondialdehyde (MDA) content, respectively; D,E show changes in DNA and RNA fluorescence intensity, detected at $364 \mathrm{~nm}$ and $400 \mathrm{~nm}$; F shows changes in the peptidoglycan content. Error bar indicates SEM.

Table 2. Fatty acid composition of the Staphylococcus aureus cell membrane following treatment with juglone for $2 \mathrm{~h}$.

\begin{tabular}{|c|c|c|c|c|}
\hline Fatty Acid Species & Control (\%) & $12.5 \mu \mathrm{g} / \mathrm{mL}(\%)$ & 25 g/mL (\%) & $37.5 \mu \mathrm{g} / \mathrm{mL}(\%)$ \\
\hline $\mathrm{C} 8: 0$ & 1.16 & 1.45 & 1.31 & 1.49 \\
\hline C10:0 & 2.27 & 2.06 & 1.97 & 1.93 \\
\hline $\mathrm{C} 12: 0$ & 1.61 & 1.53 & 1.45 & 1.55 \\
\hline C14:0 & 2.96 & 2.98 & 3.06 & 3.16 \\
\hline $\mathrm{C} 16: 1$ & 20.34 & 21.03 & 21.56 & 21.93 \\
\hline C16:0 & 17.21 & 17.03 & 16.52 & 16.4 \\
\hline C18:2 & 6.29 & 6.14 & 5.62 & 5.21 \\
\hline C18:1 & 7.64 & 7.85 & 7.92 & 7.96 \\
\hline $\mathrm{C} 18: 0$ & 21.03 & 20.36 & 19.14 & 18.64 \\
\hline UFA & 27.98 & 28.88 & 29.48 & 29.89 \\
\hline SFA & 38.24 & 37.39 & 35.66 & 35.01 \\
\hline SFA/UFA & 1.37 & 1.3 & 1.21 & 1.17 \\
\hline
\end{tabular}

$C n_{1}: n_{2}, n_{1}$ and $n_{2}$ represent the number of carbon atoms and olefinic bonds, respectively; SFA, saturated fatty acids, shown as the sum of C16:0 and C18:0; UFA, unsaturated fatty acids, shown as the sum of C16:1 and C18:1.

In conclusion, this work describes the investigation of the mechanism of action (antibacterial activity) of juglone, a plant-derived 1,4-naphthoquinone. In particular, iTRAQ technology was applied for analysis of the 53 proteins found to be differentially expressed after treatment with juglone, a plant-derived 1,4-naphthoquinone. Combined with verification experiments, the results suggest that oxidative damage was the primary S. aureus cell-killing mechanism. In the induction process, juglone up-regulated oxidoreductase, thereby enhancing the redox process and subsequently creating a peroxidative environment in the cell. In addition, juglone significantly decreased cell wall formation, inhibited cell membrane formation, and increased membrane permeability. However, this study had 
several limitations. Only one strain of ATCC6538 was used because of funding limitations. Juglone may show a different mechanism of action against other species of bacteria (e.g., Escherichia coli, Bacillus subtilis, Penicillium sp., Aspergillus sp., and Hansenula sp.), and future studies should investigate the effects of juglone on these species. In addition, these data do not comprehensively reveal the antibacterial mechanisms of juglone against $S$. aureus, and have not, for example, identified potential drug targets. Future studies could employ methods such as cocrystallization, AutoDock, and subcellular proteomic analysis to fully reveal the mechanism of action.

\section{Materials and Methods}

\subsection{Strain and Juglone}

S. aureus ATCC6538 was purchased from the American Type Culture Collection. The minimal inhibition concentration (MIC) of juglone (Sigma, St Louis, MO, USA) against S. aureus is $37.5 \mu \mathrm{g} / \mathrm{mL}$ [7].

\subsection{Culture Preparation}

Juglone (dissolved in anhydrous ethanol) was incubated with $S$. aureus during the exponential growth phase at final concentrations of $0 \mu \mathrm{g} / \mathrm{mL}, 12.5 \mu \mathrm{g} / \mathrm{mL}, 25 \mu \mathrm{g} / \mathrm{mL}$, and $37.5 \mu \mathrm{g} / \mathrm{mL}$ in beef extract peptone medium for $24 \mathrm{~h}$ at $37^{\circ} \mathrm{C}$, and a control group was incubated with anhydrous ethanol. Each different concentration group included three biological replicates. Cultures were harvested at 12 time points: $0 \mathrm{~h}, 2 \mathrm{~h}, 3 \mathrm{~h}, 4 \mathrm{~h}, 6 \mathrm{~h}, 8 \mathrm{~h}, 9 \mathrm{~h}, 12 \mathrm{~h}, 15 \mathrm{~h}, 18 \mathrm{~h}, 21 \mathrm{~h}$ and $24 \mathrm{~h}$.

\subsection{Protein Preparation}

To quantify changes to the proteome after treatment with juglone, the cultures were incubated with juglone during the exponential growth phase at a final concentration of $18.75 \mu \mathrm{g} / \mathrm{mL}$ for $2 \mathrm{~h}$ at $37^{\circ} \mathrm{C}$. Then quartz sand and $1 \mathrm{~mL}$ of SDT lysate (4\% SDS, $1 \mathrm{mM}$ DTT, $100 \mathrm{mM}$ Tris- $\left.\mathrm{HCl}, \mathrm{pH} 7.6\right)$ were added to each group and subjected to 10 rounds of homogenization. The homogenate was sonicated on ice. After 5 min of incubation in boiling water and 5 rounds of further homogenization, the crude extract was then incubated in boiling water for $10 \mathrm{~min}$ and clarified by centrifugation at $13,400 \times g$ for $30 \mathrm{~min}$. The supernatant was filtered through a $0.22-\mu \mathrm{m}$ membrane, and proteins were quantified using a bicinchoninic acid (BCA) protein assay (Beyotime, Shanghai, China).

\subsection{Protein Digestion and iTRAQ Labeling}

Total protein from each sample was digested using filter-aided proteome preparation (FASP) method as described previously by Wisniewski et al. [26], and the peptide mixture was labeled with 8-plex iTRAQ reagent (AB SCIEX, Framingham, MA, USA) according to the manufacturer's instructions.

\subsection{Strong Cation-Exchange Chromatography (SCX) Fractionation}

To reduce sample complexity, the labeled peptides were dissolved with $2 \mathrm{~mL}$ buffer A (10 mM $\mathrm{KH}_{2} \mathrm{PO}_{4}$ in $25 \% \mathrm{ACN}, \mathrm{pH} 3.0$ ) and separated by SCX chromatography (GE Healthcare) using a PolySULFOETHYL column $(4.6 \times 100 \mathrm{~mm}, 5 \mu \mathrm{m}, 200 \AA$, PolyLC Inc., Columbia, MD, USA). The elution was performed at a flow rate of $1 \mathrm{~mL} / \mathrm{min}$ with a gradient of $0 \%-10 \%$ buffer $\mathrm{B}(500 \mathrm{mM} \mathrm{KCl}, 10 \mathrm{mM}$ $\mathrm{KH}_{2} \mathrm{PO}_{4}$ in $25 \% \mathrm{ACN}, \mathrm{pH} 3.0$ ) for $2 \mathrm{~min}, 10 \%-20 \%$ buffer B for $25 \mathrm{~min}, 20 \%-45 \%$ buffer $\mathrm{B}$ for $5 \mathrm{~min}$, and $50 \%-100 \%$ buffer $B$ for $5 \mathrm{~min}$. The absorbance wavelength was set at $214 \mathrm{~nm}$, and fractions were collected every $1 \mathrm{~min}$. The collected petides were combined into 6 fractions, desalted using a C18 cartridges (Empore SPE Cartridges C18 (standard density), bed I.D. $=7 \mathrm{~mm}$, volume $=3 \mathrm{~mL}$, Sigma), and concentrated by vacuum centrifugation. Finally, the dried fractions were reconstituted in $40 \mu \mathrm{L}$ of $0.1 \%(v / v)$ trifluoroacetic acid, and stored at $-80^{\circ} \mathrm{C}$ for further liquid chromatography electrospray ionization tandem mass spectrometry (LC-ESI-MS/MS) analysis. 


\subsection{LC-ESI-MS/MS}

A quantity of $5 \mu \mathrm{g}$ of peptide mixture was separated by Easy nLC system using a C18-reversed phase column (Easy nLC system, Thermo Scientific Easy Column) $(100 \mathrm{~mm} \times 75 \mu \mathrm{m}, 3 \mu \mathrm{m})$. The separation was achieved using a linear gradient of buffer B ( $80 \%$ acetonitrile and $0.1 \%$ formic acid) at a flow rate of $250 \mathrm{~nL} / \mathrm{min}$ over $140 \mathrm{~min}$. Q Executive mass spectrometer (Thermo Fisher Scientific, Waltham, MA, USA) acquired data was filtered by choosing the most abundant precursor ions, with a range of 300-1800 m/z for higher-energy collisional dissociation (HCD) fragmentation. The target value was determined basing on predictive Automatic Gain Control (pAGC). Dynamic exclusion was used with $1 \mathrm{~min}$. Survey scans were set as a resolution of 70,000 at $\mathrm{m} / \mathrm{z} 200$, and 17,500 at $\mathrm{m} / \mathrm{z} 200$ resolution for HCD spectra. The normalized collision energy was $30 \mathrm{eV}$ and the underfill ratio, which specifies the minimum percentage of the target value likely to be reached at maximum fill time, was defined as $0.1 \%$. The instrument was run with mode enabled peptide recognition.

\subsection{Database Searching and Data Analysis}

MS/MS spectra were identified by using the Mascot engine (Matrix Science, London, UK; version 2.2) to search the UniProt S. aureus NCTC8325 database (downloaded May 2015, 2896 sequences). Proteome Discover was used to identify the proteins. The following detailed options were selected: peptide mass tolerance $= \pm 20 \mathrm{ppm}$; MS $/ \mathrm{MS}$ tolerance $=0.1 \mathrm{Da}$; enzyme $=$ trypsin, missed cleavage $=2$; fixed modification: carbamidomethyl $(C)$, iTRAQ 8-plex $(K)$, iTRAQ 8-plex (N-term); variable modification: oxidation $(\mathrm{M})$; decoy database pattern $=$ reverse.

The Mascot search results for each SCX elution were further processed using Proteomics Tools (Matrix Science, Boston, MA, USA) (version 3.05), which includes the programs BuildSummary, Isobaric Labeling Multiple File Distiller, and Identified Protein iTRAQ Statistic Builder. The BuildSummary program was used for assembling protein identifications based on a target-decoy search in shotgun proteomics. All reported data were based on $99 \%$ confidence in protein identification as determined by the peptide false discovery rate (FDR) $\leqslant 1 \%$ [27].

The programs Isobaric Labeling Multiple File Distiller and Identified Protein iTRAQ Statistic Builder were used to calculate protein ratios. The final protein ratios were then normalized by the median average protein ratio for unequal amounts of the labeled samples.

\subsection{Statistical and Bioinformatics Analysis}

Comparisons between treatment and control groups were performed using $t$-tests. Differentially expressed proteins were classified using the following scale: more than 1.2-fold $(p<0.05)$ or less than 0.83-fold $(p<0.05)[28]$.

Gene ontology (GO) analysis was performed using Blast2Go version 3.0; the detailed procedure was described by Stefan et al. [29].

\subsection{Detection of Changes in DNA and RNA Content}

Culture samples ( $2 \mathrm{~mL}$, collected at $0 \mathrm{~h}, 3 \mathrm{~h}, 6 \mathrm{~h}, 9 \mathrm{~h}, 12 \mathrm{~h}, 15 \mathrm{~h}, 18 \mathrm{~h}, 21 \mathrm{~h}$, and $24 \mathrm{~h}$ ) were centrifuged at $4000 \times g$ for $10 \mathrm{~min}$. The precipitates were washed with PBS buffer three times using centrifugation at $4000 \times g$ for $5 \mathrm{~min}$, and then dissolved in sterile water to prepare 1-mL bacterial suspensions. Next, $0.3 \mathrm{~mL}$ of each bacterial suspension was mixed with $0.9 \mathrm{~mL}$ of DAPI, and absorbance was detected at $364 \mathrm{~nm}$ (DNA) and $400 \mathrm{~nm}$ (RNA).

\subsection{Peptidoglycan Content Determination}

Glucosamine standard solution $(50 \mu \mathrm{g} / \mathrm{mL})$ was aliquoted into 6 burets $(0 \mathrm{~mL}, 0.5 \mathrm{~mL}, 1.0 \mathrm{~mL}$, $1.5 \mathrm{~mL}, 2.0 \mathrm{~mL}$, and $2.5 \mathrm{~mL}$ ), and $1 \mathrm{~mL}$ of acetylacetone was added, along with sterile water to $6 \mathrm{~mL}$. After $30 \mathrm{~min}$ of incubation in boiling water, $4 \mathrm{~mL}$ of anhydrous ethanol and $1 \mathrm{~mL}$ of Ehrlich's reagent 
were added to the cooled solution. The resulting mixture was then incubated in $60{ }^{\circ} \mathrm{C}$ water for $1 \mathrm{~h}$, and absorbance was detected at $530 \mathrm{~nm}$. Absorbance values were used to construct a standard curve.

Then, 10-mL culture samples $(0 \mathrm{~h}, 2 \mathrm{~h}, 4 \mathrm{~h}$, and $8 \mathrm{~h})$ were subjected to five repeated cycles of freezing and thawing, and sonicated on ice. The resulting mixture was centrifuged at $1000 \times g$ for $10 \mathrm{~min}$, and the supernatant was centrifuged at $10,000 \times g$ for $20 \mathrm{~min}$. After three rounds of washing, the crude peptidoglycan pellets were collected, and $2 \mathrm{mg}$ of dried material was added to $1.5 \mathrm{~mL}$ of hydrochloric acid (6 mol/L) and incubated in boiling water for $1 \mathrm{~h}$. Sodium hydroxide was added to the cooled solution to reach $\mathrm{pH} 7$, and sterile water was added to a total volume of $10 \mathrm{~mL}$. Finally, the concentration of peptidoglycan was calculated as described in the previous paragraph, and the values were used to construct a standard curve, with the following modification: $2 \mathrm{~mL}$ of the mixture was used rather than the glucosamine standard solution.

\subsection{Determination of the Extent of Oxidative Damage}

Cultures $(0 \mathrm{~h}, 2 \mathrm{~h}, 4 \mathrm{~h}, 8 \mathrm{~h}$, and $24 \mathrm{~h})$ were centrifuged at $4000 \times \mathrm{g}$ for $10 \mathrm{~min}$, and then washed with PBS three times. After resuspension in $2 \mathrm{~mL}$ of normal saline (NS), the mixture was sonicated on ice and centrifuged $\left(12,000 \times g, 20 \mathrm{~min}, 4^{\circ} \mathrm{C}\right)$ and the supernatant was collected. Concentrations of SOD, CAT, MDA, and proteins were determined according to the manufacturer's instructions (Beyotime, Shanghai, China).

\subsection{Phospholipid Extraction}

Cultures ( $2 \mathrm{~h}$ ) were centrifuged at $10,000 \times g$ for $5 \mathrm{~min}$, and the cell pellets were washed with PBS three times. After resuspension in NS, samples were sonicated on ice and two volumes of chloroform-methanol $(2: 1, v / v)$ were added; the mixture was vortexed for a further 30 min. After centrifugation $(2,500 \times g, 10 \mathrm{~min})$, the lower phase was transferred to a new tube. The mixture was added into a quarter volume of methanol-water $(1: 1, v / v)$, and the lower phase was concentrated to $1 \mathrm{~mL}$. Finally, the concentrate was vacuum-dried and stored until use.

\subsection{Gas Chromatography Analysis of Fatty Acids}

Dried phospholipids $(0.02 \mathrm{~g})$ were added to $0.5 \mathrm{~mL}$ of benzene-petroleum ether $(1: 1, V / V)$, and then $1.5 \mathrm{~mL}$ of potassium hydroxide-methanol $(0.4 \mathrm{~mol} / \mathrm{L})$ was added. After incubation in $50{ }^{\circ} \mathrm{C}$ water for $15 \mathrm{~min}$, hexane was added to the cooled solution to a total volume of $10 \mathrm{~mL}$. Samples were vortexed, and the lower phase was collected for gas chromatography analysis. The following parameters were used for gas chromatography: a $30 \mathrm{~m} \times 0.32 \mathrm{~mm} \times 0.25 \mu \mathrm{m}$ cp-Sil 19 CB silica capillary column was used; the temperature program ramped from $40{ }^{\circ} \mathrm{C}(2 \mathrm{~min}$ hold $)$ to $260^{\circ} \mathrm{C}(1 \mathrm{~min}$ hold $)$ at $3{ }^{\circ} \mathrm{C}$ per minute; the injector and detector were held at $250{ }^{\circ} \mathrm{C}$ and $300{ }^{\circ} \mathrm{C}$, respectively, with nitrogen used as the carrier gas; the flow rate was $2 \mathrm{~mL} / \mathrm{min}$, and the injection volume and split ratio were $1 \mu \mathrm{L}$ and 35:1 respectively. Finally, a standard mixture that included 37 types of fatty acid methyl esters (Sigma, St. Louis, MO, USA) was used to determine the relative content of fatty acids through area normalization processing.

Acknowledgments: This work was financially supported by the National Natural Science Foundation of China (Grant No. 31270721).

Author Contributions: Zhaoxia Wu and Jiayi Wang were responsible for designing the study, performing the experiments, collecting and analysing the data, and writing the manuscript. Yuhuan Cheng and Rina $\mathrm{Wu}$ contributed to experiment design, data processing, and experiment performing. Bing Bai, Donghua Jiang, Dehong Tan, Tingcai Yan, Xiyun Sun, and Qi Zhang contributed to procuring experimental materials and equipment support, parts of experiment operation, and data analysis.

Conflicts of Interest: The authors declare no conflict of interest. 


\section{Abbreviations}

$\begin{array}{ll}\text { BCA } & \text { bicinchoninic acid } \\ \text { FASP } & \text { filter-aided proteome preparation } \\ \text { FBD } & \text { food-borne diseases } \\ \text { FDR } & \text { false discovery rate } \\ \text { GO } & \text { gene ontology } \\ \text { HCD } & \text { higher-energy collisional dissociation } \\ \text { iTRAQ } & \text { isobaric tags for relative and absolute quantitation } \\ \text { LC-ESI-MS/MS } & \text { liquid chromatography electrospray ionization tandem mass spectrometry } \\ \text { MDA } & \text { malondialdehyde } \\ \text { MIC } & \text { minimal inhibition concentration } \\ \text { MS2 } & \text { second-level mass spectrometry } \\ \text { ROS } & \text { reactive oxygen species } \\ \text { SEs } & \text { staphylococcal enterotoxins } \\ \text { SFA } & \text { saturated fatty acids } \\ \text { SFP } & \text { staphylococcal food poisoning } \\ \text { SOD } & \text { superoxide dismutase } \\ \text { TAG } & \text { triacylglycerols } \\ \text { UFA } & \text { unsaturated fatty acids } \\ \text { WHO } & \text { World Health Organization } \\ \text { GTP } & \text { guanosine triphosphate } \\ \text { CTP } & \text { cytidine triphosphate } \\ \text { CAT } & \text { catalase }\end{array}$

\section{References}

1. Kadariya, J.; Smith, T.C.; Thapaliya, D. Staphylococcus aureus and staphylococcal food-borne disease: An ongoing challenge in public health. Biomed. Res. Int. 2014, 2014, 827965. [CrossRef] [PubMed]

2. Friedman, M.; Rasooly, R. Review of the inhibition of biological activities of food-related selected toxins by natural compounds. Toxins 2013, 5, 743-775. [CrossRef] [PubMed]

3. Hennekinne, J.A.; de Buyser, M.L.; Dragacci, S. Staphylococcus aureus and its food poisoning toxins: Characterization and outbreak investigation. FEMS Microbiol. Rev. 2012, 36, 815-836. [CrossRef] [PubMed]

4. Gallina, S.; Bianchi, D.M.; Bellio, A.; Nogarol, C.; Macori, G.; Zaccaria, T.; Biorci, F.; Carraro, E.; Decastelli, L. Staphylococcal poisoning foodborne outbreak: Epidemiological investigation and strain genotyping. J. Food Prot. 2013, 76, 2093-2098. [CrossRef] [PubMed]

5. Pinchuk, I.V.; Beswick, E.J.; Reyes, V.E. Staphylococcal enterotoxins. Toxins 2010, 2, 2177-2197. [CrossRef] [PubMed]

6. Babula, P.; Adam, V.; Havel, L.; Kizek, R. Noteworthy secondary metabolites naphthoquinones-Their occurrence, pharmacological properties and analysis. Curr. Pharm. Anal. 2009, 5, 47-68. [CrossRef]

7. Wu, Z.; Chen, G.; Wang, Y. Inhibition effect of juglong on several food deterioration microorganisms. China Brew. 2009, 8, 76-78.

8. Padayatty, S.J.; Katz, A.; Wang, Y.; Eck, P.; Kwon, O.; Lee, J.-H.; Chen, S.; Corpe, C.; Dutta, A.; Dutta, S.K.; et al. Vitamin c as an antioxidant: Evaluation of its role in disease prevention. J. Am. Coll. Nutr. 2003, 22, 18-35. [CrossRef] [PubMed]

9. Ji, L.L. Antioxidants and oxidative stress in exercise. Exp. Biol. Med. 1999, 222, 283-292. [CrossRef]

10. Paiva, S.A.R.; Russell, R.M. B-carotene and other carotenoids as antioxidants. J. Am. Coll. Nutr. 1999, 18, 426-433. [CrossRef] [PubMed]

11. Ferland, G. The discovery of vitamin k and its clinical applications. Ann. Nutr. Metab. 2012, 61, $213-218$. [CrossRef] [PubMed]

12. Hofmeister, A.E.; Grabowski, R.; Linder, D.; Buckler, W. L-serine and l-threonine dehydratase from clostridium propionicum two enzymes with different prosthetic groups. Eur. J. Biochem. 1993, 215, 341-349. [CrossRef] [PubMed]

13. Sobota, J.M.; Imlay, J.A. Iron enzyme ribulose-5-phosphate 3-epimerase in escherichia coli is rapidly damaged by hydrogen peroxide but can be protected by manganese. Proc. Natl. Acad. Sci. USA 2011, 108, 5402-5407. [CrossRef] [PubMed]

14. Iwata-Reuyl, D. Biosynthesis of the 7-deazaguanosine hypermodified nucleosides of transfer rna. Bioorg. Chem. 2003, 31, 24-43. [CrossRef] 
15. Zhang, R.L.; Hirsch, O.; Mohsen, M.; Samuni, A. Effects of nitroxide stable radicals on juglone cytotoxicity. Arch. Biochem. Biophys. 1994, 312, 385-391. [CrossRef] [PubMed]

16. Klaus, V.; Hartmann, T.; Gambini, J.; Graf, P.; Stahl, W.; Hartwig, A.; Klotz, L.O. 1,4-naphthoquinones as inducers of oxidative damage and stress signaling in hacat human keratinocytes. Arch. Biochem. Biophys. 2010, 496, 93-100. [CrossRef] [PubMed]

17. Saify, Z.S.; Mushtaq, N.; Noor, F.; Takween, S.; Arif, M. Role of quinone moiety as antitumour agents: A review. Pak. J. Pharm. Sci. 1999, 12, 21-31. [PubMed]

18. Alvarez, H.M.; Steinbuchel, A. Triacylglycerols in prokaryotic microorganisms. Appl. Microbiol. Biotechnol. 2002, 60, 367-376. [PubMed]

19. Hecker, M.; Volker, U. General stress response of bacillus subtilis and other bacteria. Adv. Microb. Physiol. 2001, 44, 35-91. [PubMed]

20. Wozniak, D.J.; Tiwari, K.B.; Soufan, R.; Jayaswal, R.K. The mcsb gene of the clpc operon is required for stress tolerance and virulence in staphylococcus aureus. Microbiology 2012, 158, 2568-2576. [CrossRef] [PubMed]

21. Overton, T.W.; Justino, M.C.; Li, Y.; Baptista, J.M.; Melo, A.M.; Cole, J.A.; Saraiva, L.M. Widespread distribution in pathogenic bacteria of di-iron proteins that repair oxidative and nitrosative damage to iron-sulfur centers. J. Bacteriol. 2008, 190, 2004-2013. [CrossRef] [PubMed]

22. Brunskill, E.W.; de Jonge, B.L.; Bayles, K.W. The staphylococcus aureus scda gene: A novel locus that affects cell division and morphogenesis. Microbiology 1997, 143, 2877-2882. [CrossRef] [PubMed]

23. Chang, W.; Small, D.A.; Toghrol, F.; Bentley, W.E. Global transcriptome analysis of staphylococcus aureus response to hydrogen peroxide. J. Bacteriol. 2006, 188, 1648-1659. [CrossRef] [PubMed]

24. Freiberg, C.; Brunner, N.A.; Schiffer, G.; Lampe, T.; Pohlmann, J.; Brands, M.; Raabe, M.; Habich, D.; Ziegelbauer, K. Identification and characterization of the first class of potent bacterial acetyl-coa carboxylase inhibitors with antibacterial activity. J. Biol. Chem. 2004, 279, 26066-26073. [CrossRef] [PubMed]

25. De Smet, M.J.; Kingma, J.; Witholt, B. The effect of toluene on the structure and permeability of the outer and cytoplasmic membranes of escherichia coli. BBA Biomembr. 1978, 506, 64-80. [CrossRef]

26. Wisniewski, J.R.; Zougman, A.; Nagaraj, N.; Mann, M. Universal sample preparation method for proteome analysis. Nat. Meth. 2009, 6, 359-362. [CrossRef] [PubMed]

27. Sandberg, A.; Lindell, G.; Källström, B.N.; Branca, R.M.; Danielsson, K.G.; Dahlberg, M.; Larson, B.; Forshed, J.; Lehtiö, J. Tumor proteomics by multivariate analysis on individual pathway data for characterization of vulvar cancer phenotypes. Mol. Cell. Proteom. MCP 2012, 11. [CrossRef] [PubMed]

28. Gan, C.S.; Chong, P.K.; Pham, T.K.; Wright, P.C. Technical, experimental, and biological variations in isobaric tags for relative and absolute quantitation (itraq). J. Proteome Res. 2007, 6, 821-827. [CrossRef] [PubMed]

29. Gotz, S.; Garcia-Gomez, J.M.; Terol, J.; Williams, T.D.; Nagaraj, S.H.; Nueda, M.J.; Robles, M.; Talon, M.; Dopazo, J.; Conesa, A. High-throughput functional annotation and data mining with the blast2go suite. Nucleic Acids Res. 2008, 36, 3420-3435. [CrossRef] [PubMed]

(C) 2016 by the authors; licensee MDPI, Basel, Switzerland. This article is an open access article distributed under the terms and conditions of the Creative Commons Attribution (CC-BY) license (http://creativecommons.org/licenses/by/4.0/). 